\title{
O Amor e a lei \\ O Processo de Separação no Tribunal de Família
}

"Qual é o traumatismo que interessa ao psicanalista, senão o do amor? Sem dúvida é um paradoxo comparar o amor a um fato violento, mas não é o que acontece quando aquele a quem o impulso do coração apela é um sedutor que se esquiva?" (Pommier, 1992)

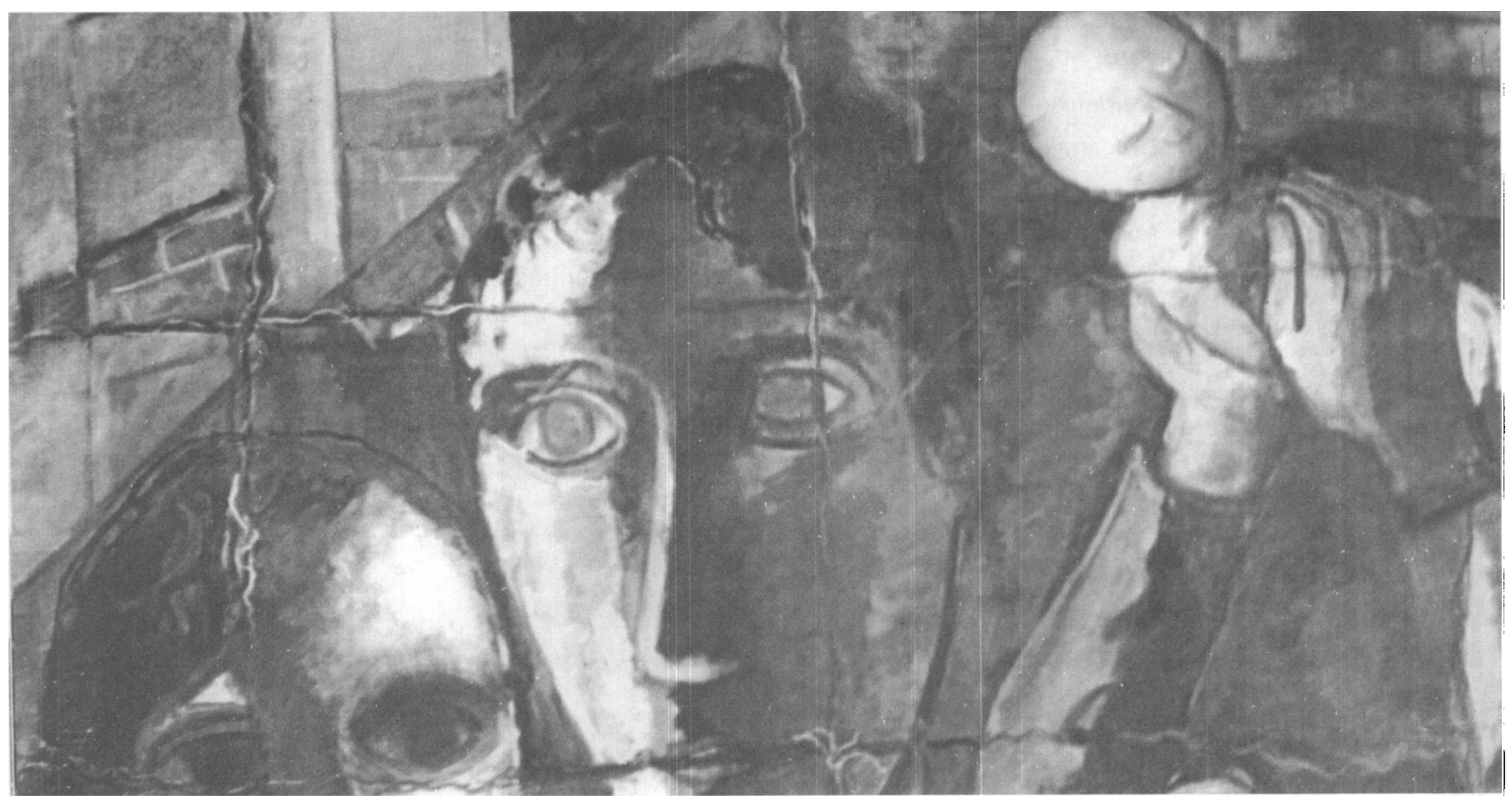

\section{"A}

sexualidade é sempre traumática."(Lacan,1975).

Aquele a quem amamos diretamente ou pelo avesso, corresponda ao nosso apelo ou dele se esquive, tem sempre a estrutura de um objeto, pois empresta seu corpo para que nossas fantasias sejam ali depositadas.

\section{Fernanda Otoni} de Barros

Psicanalista Psicóloga Judicial do Tribunal de Justiça do Estado de Minas Gerais Membro da Associação iberoamericana de Psicologia Juridica
Nas Varas de Família ouvimos o eco das apelações insatisfeitas, os desencontros amorosos causando a demanda de uma reparação, esperando que a lei possa colocar-se em boa posição, regular o irregulável.

A frustração conjugal ao criar a demanda jurídica provoca a instituição de uma lei. Os operadores jurídicos são chamados para intervir neste terreno criado pelos artifícios da subjetividade humana, as normas colocam-se na função de regular o caos deflagrado, a objetividade jurídica encontra-se diante do muro que a trama subjetiva das relações impõe... "o que não tem governo e nem nunca terá, o que não tem juízo..."(Buarque, 1976) 
Em matéria de Direito de Família o mal estar causado pelo desencontro amoroso, pelo mal entendido próprio do litígio conjugal, tem letras, páginas e nome próprio: processo de separação.

Trata-se de uma separação... um tempo que destina-se a perder esse objeto antes adorado, agora degradado, mas que ainda está em cena no teatro das utopias, a serviço da alienação, encobrindo o real do desamparo que toda separação revela.

Tramas e dramas tecidos pelos arranjos da conjugalidade, pelas ficções construídas por cada cônjuge envolvido no processo judicial atravessam as páginas dos autos processuais "como se" fossem a expressão da verdade.

Por outro lado, a pressuposta neutralidade do juiz na leitura e interpretação do texto da lei, na análise das provas de cada caso e em toda condução do processo configura-se como mais uma ficção do Direito pois não desconsideramos a interferência da subjetividade do jurista na formulação de sua convicção e na construção da sentença.

Está em dia a frase: Cada cabeça uma sentença.

O Tribunal de Família é um campo onde a ficção desfila. Em Direito de Família, onde a questão da moral e da subjetividade colocamse de forma determinante, é grande a tendência em permitir que valores morais e pessoais sirvam de tela na interpretação do comportamento alheio.

Porque o Tribunal de Família torna-se um terreno fértil para as projeçōes subjetivas?

Dentre as várias possibilidades de responder a esta questão, podemos pensar que a cena apresentada no processo litigioso é aquela constitutiva da sexualidade humana, em suas possíveis e inimagináveis vestes, onde as partes litigantes tornam público o testemunho de uma experiência íntima, privada.

Atos e pactos consentidos na experiência da conjugalidade são oferecidos ao olhar do Tribunal causando horror, capturando o Juízo com argumentos e cenas impactantes, fora da estrutura prevista pela ordem moral e social. Tais cenas foram, na maioria das vezes, vividas e permitidas durante o pacto conjugal, de acordo com a estrutura subjetiva, de acordo com as tramas simbólicas que enredam o sujeito amoroso em um jeito de amar que constitui uma situação de amor.

As relações expostas sem cobre leitos, desnudas de sua privacidade horrorizam e sob efeito d'isso precipitam posições defensivas ou paralisantes, cai o ideal de neutralidade e veremos fantasias em cascatas produzindo a leitura do processo.

Capturados pelas ditames das próprias fantasias, pela lei do particular, teremos como instrumento condutor o próprio inconsciente.

É importante considerar a ambiguidade peculiar a toda estrutura subjetiva, seus arranjos simbólicos, a via de mão dupla pela qual esta transita, a divisão que ela causa... pode ser de um jeito mas também suporta o seu avesso.

A Justiça como uma demanda simbólica também padece desses atributos... o que se pede quando clama-se por justiça?

A Justiça enquanto ideal é uma ficção, cada um tem uma ideia sobre isso... Basta perguntar o que é Justiça que encontraremos uma infinidade de arranjos simbólicos tentando definir tal conceito que permanece inatingível enquanto algo objetivável, sendo sempre na ordem do singular a sua apropriação. $O$ sujeito jurídico e a justiça são noções ideológicas e ficcionais.

Hans Kelsen já dizia... "a justiça é um bem que se demanda porque não é dada..."(1974) portanto, para fazer justiça faz-se necessário
"Ah! Mas o amor em que não crêem continua gerando sentenças justas gerando bençãos e amantes,

apesar do morto e seu pescoço arruinado." (Adélia Prado) 
O Tribunal de Familia é um campo onde a ficção desfila operar os dispositivos do direito para fazer valer a justiça possível, ou seja, o texto da lei que todos devem saber.

Perguntaram a Jesus: "Como fazer para ser bom e só fazer o bem?" Jesus respondeu: Bom só Um o é, portanto deves seguir os mandamentos"... o que está no texto da lei, pois nada pode garantir o bem e o bom... a estrutura pode falhar e falha, portanto é necessário que haja um texto a seguir, onde haja o exercício da justiça do possível.

Se todos amássemos uns aos outros em harmonia, se esta estrutura fosse infalivel, não haveria necessidade do mandamento, da lei. Há a lei porque esta estrutura manca, pois, muitas vezes o ódio que advém de um ato diferente de nosso desejo nos faz idealizar uma sociedade de iguais... arquitetar um plano diabólico que iria extinguir do mundo tudo aquilo que se encontrasse entre o desejo e sua realização, uma necessidade de aniquilar aquilo que é desigual ao ideal... faríamos isto toda vez que o outro nos desse a medida de nossa frustração... se não houvesse lei... se não estivesse escrito em algum lugar que poderá haver um retorno desse ato sobre nós.

E só está escrito porque vivemos numa civilização e esta é plural e não igual como desejaríamos que fosse em nossos inconfessáveis sonhos... (que a civilização fosse a extensão da ditadura do desejo. Um império sem limites.)

\section{Poderíamos escutar a exposição de motivos daquele que comete um ato fora da lei:}

"Não te amo mais, por me traires, não encontrar onde procuro o que não há... Por tanto mato, degrado, roubo, executo neste corpo sem meu gosto a marca do meu gozo. Mesmo que digam não... é esta a ordem que me invade... vou ao ato pois tenho urgência higiênica... de fazer precipitar deste lugar que me enlouquece um objeto qualquer. $\mathrm{E}$ depois deste ato, me desato e encontro nesta carne podre o sem-sentido exato do meu desprezo... não te amo mais."E a lei sobre este dirá: És responsável por seu ato, descumpriu o projeto da civilização. Para ser cidadão é preciso reconhecer a lei da cidade que diz: "Deverás amar o próximo como a ti mesmo."

Este recorte ilustra a especificidade da estrutura subjetiva, pois um sujeito nunca se relaciona com outro sujeito e sim com um objeto, é o reconhecimento da existência do outro que nos permite perceber que lá onde desejamos um objeto idêntico as nossas fantasias e desejo, insiste a diferença, ou seja, o sujeito inapreensível em sua singularidade, inexplicável e que faz mancar a demanda objetal.

Bem... O que fazer da nossa prática, uma vez que no mundo nada está preparado para trazer ao homem satisfação, uma vez que o homem não pode formular nenhum princípio para o seu desejo, uma vez que ele não pode tudo dizer...tudo saber e que não existe nem existirá uma ordem moral ou social que corresponda aos seus anseios, que the garanta felicidade e harmonia?

A ética nos aponta que não devemos recuar diante da possibilidade de construção de uma nova posição diante do Outro,

"A metáfora do laço social significa essencialmente, metabolizar e humanizar o discurso do Outro, assinalando ao poder e aos sujeitos a sua posição no espaço das trocas humanas." (Legendre, 1983), portanto um lugar a ser inventado em cada caso, espaço da diferença, um lugar problematizado.

É inegável o entrelaçamento entre Direito de Família e a estrutura subjetiva das relações: lugar contraditório, onde o instrumento jurídico é insuficiente para dar conta de se inserir dentro da objetividade que este campo almeja, pois o fenômeno do impasse litigioso ocorre num terreno onde a antino- 
mia e a ambiguidade são elementos relevantes, próprios do campo simbólico, da estrutura da ficção.

Entrelaçamento que abriu a possibilidade de construção de um campo denominado de 'Psicologia Jurídica', mas que teve num primeiro momento o entendimento de ser um lugar pericial... antigamente, (pensamos no tempo como lógico), era um lugar que desejava tudo saber sobre o melhor para a criança, a família e a convivência familiar adequada aos princípios da moral e da ordem pública...

\section{Era uma vez... a perícia}

O campo da psicologia jurídica inseriu-se no ordenamento jurídico, como prova processual. Seu lugar: PERÍCIA. A prova pericial é um dispositivo jurídico que auxilia na formação da convicção do Juíz, para que este julgue, intervenha na vida privada de uma forma que pode almejar ser educativa, preventiva ou punitiva. Para que o Estado determine o que é o melhor para o indivíduo e para a sociedade. O perito deve trazer aos autos um laudo com argumentos técnicos que esclareça sobre a verdade do fato posto em questão pelo Juízo.

De imediato percebemos que este modelo servia aos paradigmas de um Estado Intervencionista em oposição a concepção de um Estado Plural. Voltaremos a isto mais tarde, fica aqui apenas um recorte que aponta para a questão ideológica que perpassa a noção de verdade no campo jurídico.

Os processos são literaturas ficcionais, onde versões distintas tentam provar a sua veracidade, num desejo de tudo dizer sobre a verdade do casal. Lugar repleto de a/versões, campo imaginário e fantasmático, onde o outro é sempre responsável pelo caos deflagrado.

A psicanálise nos aponta que a verdade é sempre não toda, impossível de ser apreendida em sua consistência. Não existe uma verdade única sendo que cada um constrói a sua ficção sobre a sua história e em torno d'isso sustenta-se um saber que é transmitido e repetido "como se" fosse a verdade, mas é uma construção absolutamente particular.

"Percebemos que numa situação de litígio cada parte vem trazendo uma história e que estas histórias nunca se casam. Há um litígio para além do conjugal, um litígio estrutural que atravessa os discursos de todos desta organização familiar. Cada um do seu canto, tem uma história própria para contar, cada um defendendo a sua versão, dos pais aos filhos, transmissão do mal-entendido que estrutura todos os discursos. Esta história não é destituída de saber, mesmo diante de tantas versões, ela suporta algo da verdade do sujeito, um ponto irredutível."(Otoni de Barros, 1997)

A verdade tem sempre estrutura de ficção... já dizia Santo Agostinho... "fictio figura veritatis."

A partir da implicação da psicanálise neste campo gostaria de problematizar a atuação do perito, esta função pericial, perguntando: Onde encontrar esta verdade?

Se a psicologia jurídica tem como fundamento no campo jurídico oferecer a verdade aos autos, sabemos que esta verdade é sempre pelas metades, não é possível apreender toda a verdade do sujeito. Impossível responder à demanda de dar provas da verdade. Existem certas verdades que determinam a vida do sujeito mas que são inconscientes e desta forma inapreensíveis; o sujeito para guardálas em seu estatuto estruturante se defende delas e não as revelam, a não ser enquanto tropeços, nas entrelinhas. O que temos acesso é ao saber do sujeito em torno da sua verdade e toda estrutura de saber é ficcional.

Por outro lado, o sujeito da psicanálise é o sujeito do inconsciente de impossível apreensão na sua totalidade, pois ele só aparece quando desaparece a razão. Já o sujeito que o direito aborda é uma noção ideológica: sujeito cartesiano, livre para discernir entre o bem e o mal, consciente de
Basta perguntar o que é Justiça que encontraremos uma infinidade de arranjos simbólicos tentando definir tal conceito que permanece Inatingível enquanto algo objetivóvel. sendo sempre na ordem do singular a sua apropriação 
seus atos, segundo os paradigmas de uma ideologia da ordem pública e moral instituída por um Estado Maior.

Poderíamos dizer que existe um reconhecimento por parte do campo jurídico do sujeito do inconsciente. Ao criar o campo da "psicologia jurídica" podemos nos atrever em interpretar este ato como um reconhecimento de que existe algo no discurso apresentado nos autos que está fora de ordem, a constatação de um certo caos deflagrando atos insanos ou estranhos a um sujeito consciente de si.

A partir dessa constatação solicita-se uma perícia, esperando que o perito vasculhe a nebulosa alma humana e apresente as provas da verdade mascarada por estes atos insanos... que dê sentido ao sem sentido derramado nas páginas processuais. Ou seja, que este sujeito inconsciente, loucura anunciada nos processos, seja traduzido ao sujeito cartesiano, que o faça constar nos autos, que transforme em consciente aquilo que é inconsciente, traduzindo-o, interpretando os atos do sujeito para o Juízo.

É Gerard Pommier quem nos fala da impossibilidade de tradução do inconsciente, pois não se encontra em lugar acessível.(1990)

Aquele que vem para uma entrevista nas salas do "Setor de Psicologia Jurídica" segue uma determinação do Juiz ...querendo ou não ele tem que se submeter a esta avaliação pericial.

Este não vem disposto a falar da sua intimidade, mas vem sobretudo falar aquilo que pode Ihe favorecer para ganhar a sua verdade, advogam em causa própria, dizem o que pensam que podem e não falam sobre o que acredita ser tropeço. Trazem a escrita da sua versão numa falação ao infinito, por não querer saber daquilo que é irredutível no discurso.

Este depoimento está prejudicado pois o sujeito não está ali numa posição de quem fala de si. A resistência é consciente e isto coloca muitos limites a construção de um diagnóstico sobre estes dados escutados de uma fala mal dita.

O setting pericial não pode oferecer ao sujeito esse convite a sua aparição, pois aquilo que for dito poderá ser lido por seus "piores inimigos" e vir a público. Coisas que o sujeito guarda mesmo de si.

Qual a função de um laudo pericial que revela aquilo que ainda está velado, porque foi o resultado de testes, entrevistas, dinâmicas, etc...Qual o efeito desta revelação no campo do sujeito e em suas relações sociais e no próprio campo do direito? Qual é a ética que sustenta esta atuação no campo da "psicologia jurídica"?

"As pessoas envolvidas no processo judicial perdem num só golpe o saber que construíram sobre si e a condução da sua história de vida, alienados a um laudo que os revela numa intimidade desconhecida e submetidos a decisão de um outro (Juiz) sobre um ser onde não se reconhece.

A posição cartesiana do perito serve, apenas, para garantir a onipotência narcísica do profissional que acredita ser possível responder a demanda jurídica com a verdade cartesiana. Nada serve ao sujeito pois não provoca uma retificação subjetiva e nem serve à Justiça, pois o saber apresentado como verdade cristalizada é uma "ficção psicológica"."(Otoni de Barros, 1997)

É preciso rever os conceitos e paradigmas, para estarmos mais próximos de uma posição ética. Caso contrário a intervenção no campo jurídico de conceitos psicológicos operará como um instrumento de alienação e subordinação do sujeito à um discurso do mestre, que pretende saber sobre o que é o melhor, a serviço do poder.

Pierre Legendre, jurista e psicanalista francês, já dizia que a grande arma do poder é fazerse amar, o amor do censor, amamos aquele que tem o poder e em quem supomos o saber, numa alienação servil.(1983) 
O direito na modernidade teve sua estrutura na manutenção deste estado das coisas, que assegurou, na sociedade contemporânea, as mesmas funções e finalidades anteriormente sustentadas pelas práticas religiosas.

"O que mudou foi apenas o envólucro do discurso que, no seu interior, mantém intocável a relação de autoridade estabelecida para domesticar os homens. O que está em jogo nas tramas institucionais, como também nos textos jurídicos, é a produção e a reprodução de um fazer crer, que não modifica quanto a sua função de reger, dominar e condicionar o gênero humano."(Phillippi,1994)

O campo da "Psicologia Jurídica" serviu por muito tempo como um lugar de onde o sistema jurídico retirou instrumentos de interpretação das cenas familiares apresentadas, arraigada em crenças teóricas próprias a cada linha de pensamento psicológico, produzindo um corpo de provas, que objetivavam a reprodução do discurso da ordem, submetendo os envolvidos aos ditames deste saber. Neste campo, na análise das provas apresentadas, ou seja, dos testes psicológicos, das análises das entrevistas, das dinâmicas familiares realizadas, retirava-se o material necessário para a formulação de uma sentença psicológica, vulgo, laudo psicológico, tendo-se garantido a realização do ritual processual técnico-psicológico necessário para formulação da convicção.

Estavamos no registro da legalidade da subjetividade, ou seja, legalizar, regulamentar a subjetividade das relações através de um documento chamado parecer psicológico, estudo psicológico, laudo psicológico, como queiram... um parecer positivo.

Se no discurso da revolução francesa, "liberdade, igualdade e fraternidade" extraimos o assentamento do pensamento moderno, extraimos também a face dogmática, utópica e positivista do direito e consequentemente da "psicologia jurídica" trabalhando a serviço de uma regulamentação das relações e do comportamento, com diagnósticos positivos onde a fratura de sua inconsistência permanecia encoberta pelos suportes dogmáticos teóricos. "Todos iguais perante a lei", um movimento de exclusão da diferença.

Qual outro lugar seria possível para a Psicologia Jurídica, pensando na reformulação de seus conceitos e paradigmas, dentro da discussão atual de um estado plural, onde a diferença esteja incluída em seu projeto em oposição a um estado intervencionista que através de sua intervenção exerce o controle das demandas sociais para ajustá-las a um projeto ideológico do poder?

Um lugar a ser inventado no caso a caso, um lugar comprometido com a ética, um lugar mediador, promovendo a possibilidade de uma operação simbólica, um deslocamento da demanda... uma retificação subjetiva, onde ocorra um processo de separação.

A implicação do sujeito no processo de subjetivação conduz o deslocamento da posição alienada da vítima que necessita da proteção intervencionista do Estado para uma posição responsável de quem sustenta na própria carne a operação de perda que toda ruptura traz e assina com sua letra, de próprio punho, os termos da separação.

O que está em discussão não são as técnicas e

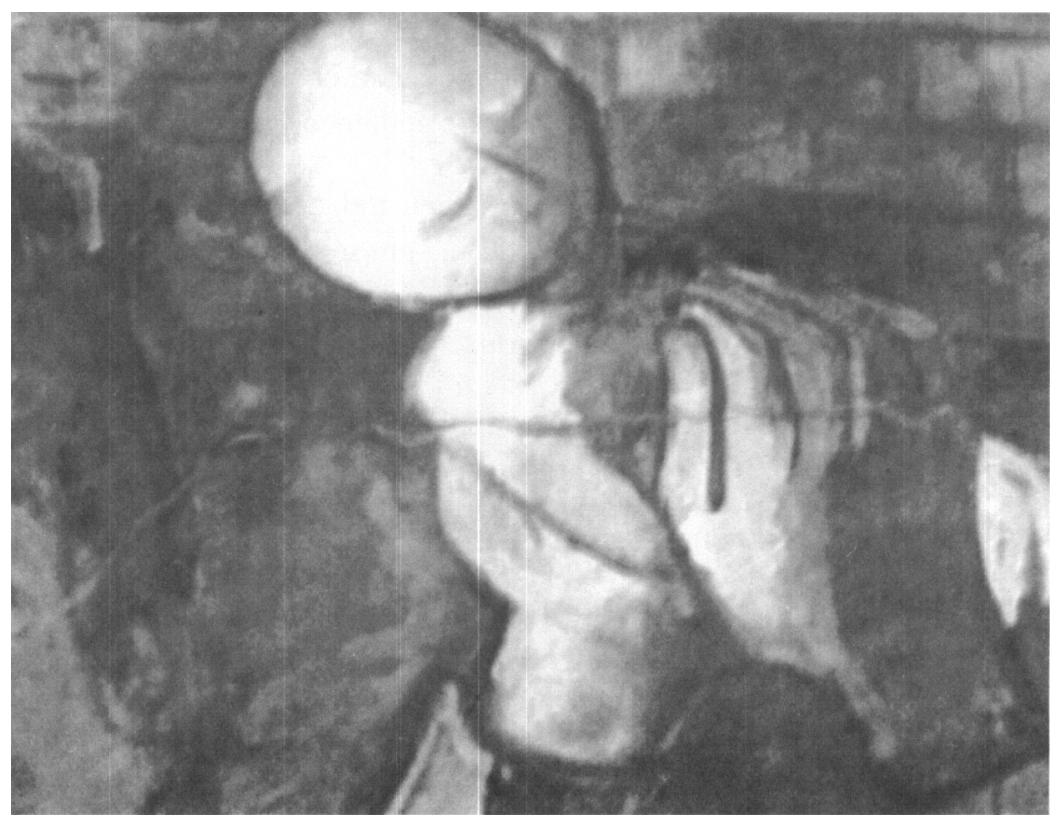


dogmas psicológicos ou jurídicos, mas um modelo de sociedade, o lugar do sujeito no projeto da civilização.

É Jeanninne Phillippi quem declara uma nova proposta para a subjetividade, a partir do estatuto de sujeito:

"Na orientação que se trata de articular com o universo subjetivo do sujeito as suas implicações simbólicas, desvendam-se lugares pouco explorados que envolvem a inscrição de seres humanos em mundos que eles próprios terão de ressignificar sem a mediatização de nenhuma instância superior que lhes retire aquilo que Ihes compete originalmente, isto é, a capacidade de construir e reconstruir os caminhos de suas existências."(1994)

\section{A Clínica no Judicial}

(A Psicanálise implicada no campo da Psicologia Jurídica)

Para além da perícia .... mediação.

A demanda endereçada ao campo jurídico é povoada de fantasias e frustrações, estrutura simbólica da demanda, coisas sobre as quais o jurídico não pode regular, mas que no campo da psicologia jurídica pode e deve haver um espaço para retificação subjetiva, ou seja, operar nesta demanda original um desbastamento que a reduza a uma demanda própria ao campo jurídico e que os restos deste recorte possam ter outro endereço.

Esta é a particularidade da subjetividade humana. Lacan, em seu Seminário "Relação de objeto", nos apresenta os tres tempos da subjetividade:

"Os três tempos da subjetividade, na medida em que esta se realciona com a frustração, sob a condição de se tomar esta última no sentido da falta de objeto, serão facilmente encontrados por vocês se refletirem inicialmente na posição zero do problema, a instituição do símbolo puro de mais ou menos, presença ou ausência, que nada mais é que a posição objetivável. (...) O segundo tempo (...) é uma espécie de demanda pela qual se situam em posição de serem gratificados ou não pela resposta do outro (...) o estágio segundo da relação dual, na medida em que se institui o apelo e a resposta, sob o qual se estabelece o nível da frustração. (...) Aterceira dimensão que lhe dá seu sentido, aquela da lei, sob uma forma que sempre está latente no exercício do jogo.(...) A instituição de uma lei ou de uma regularidade concebida como possível... é nesse momento que se estabelece o que está fundamentalmente no jogo e que the dá seu sentido intersubjetivo, situando-o numa dimensão não mais dual, e sim ternária."(1995)

No Tribunal assistimos ao que antecede a demanda - a frustração causada pela falta de objeto... o outro falta ao sujeito para responder suas fantasias - registra-se sob o nome de petição inicial a demanda jurídica, ou seja, a expressão do litígio, que é uma expectativa de retificação e recuperação da falta. $O$ próximo passo é aguardar o terceiro tempo, digo, o instituto da lei.

O campo da psicologia jurídica deve ser o de restituir àquele que a procura a dignidade de ser autor de sua história, trabalhando no sentido de promover uma implicação deste na tecitura discursiva e simbólica que apresenta, desmontando as ficções onde o sujeito se encontrava alienado, originalmente, ao enderaçar à Justiça, este Outro, os designios de sua vida.

A função deste novo campo, nesta perspectiva, seria desbastar a demanda jurídica de seus excessos fantasmáticos, para reduzí-la ao ponto que possibilite a realização da função jurídica, ou seja:" a implicação da parte naquilo que ela pede ou impede através da demanda."(Cyro Marcos da Silva-O GLOBO, 15/11/97)(12)

Ao campo jurídico restará o que lhe é próprio, ou seja, a instituição da lei onde esta não está, operando um basta na invasão do gozo, retornando ao cotidiano a necessidade de se submeter a todo instante a uma dada regularidade da ordem sobre a desordem.

Neste trabalho a verdade se reduz à verdade do sujeito e este tem que se responsabilizar pelos 
efeitos disto, de não ter provas e as garantias, de reconhecer a diferença, e desta forma reconhecer o Outro.

É um trabalho necessário e possível que resgata a responsabilidade do sujeito pelos seus atos, num reconhecimento do Outro e do desigual, extirpando a violência do direito, que ao excluir a diferença transforma-se em violento censor.

"Não são necessárias verdades absolutas e valores universais." (Baratta, 1994). É possível reconhecer a existência de um juízo alheio, diferente do nosso ideal de justiça, renunciando a violência de um juízo único, sem abandonar o direito. É o exercício de uma ética da diferença, ou seja, temos que seguir o mandamento de amar ao próximo como a si mesmo, apesar do paradoxo que este mandamento impóe.

Na distância entre eu e o outro há o espaço da diferença, o limite de nossa convivência se encontra no reconhecimento de que o próximo não é um igual e sim diferente, e para convivermos na cidade, sermos cidadãos é preciso saber desta medida, para cumprirmos a difícil tarefa de realizar o projeto de civilização.

"Se no instante da paixão, uma escultura encobria o furo, fazendo promessas, alianças... No desenlace se trata de um reencontro com o furo do conjugal, com um lugar onde não é possivel complemento, tamponamento, mas que paradoxalmente é o que possibilita continuar a desejar. Não existe um culpado pelo desencontro amoroso, pois o desencontro já estava lá na singular forma de amar. A conjugalidade é um exercício litigioso, confronto de diferenças, estruturado em torno da fiç̧ão de amor que cada um construiu, de forma ímpar. Se o amor já não faz laços ou "se o anel que tu me deste era vidro e se quebrou" , uma separação se faz necessária. Trabalharemos, a psicologia jurídica dentro ou fora dos tribunais, no sentido de escutar desta ficção singular que o sujeito apresenta, como a sua verdade, a formulação de uma saída para o impasse da conjugalidade. Uma saída sem par. Trata-se de um compromisso ético."(Otoni de Barros, 1996)

Muito ainda teremos que inventar, mas o importante é dar o primeiro passo, romper com estruturas ultrapassadas e nos lançarmos neste desafio de construir uma prática comprometida com a ética, onde a cidadania e a diferença tenham o seu lugar na construção de uma nova aliança, ou seja, um outro modo de enlaçar neste mundo as questões do amor e da lei.
Baratta, A. (1994). A Lei e o Ideal Democrático. Conferência proferida no Encontro Brasileiro de Direito e Psicanálise. Curitiba.

Buarque, C. (1976). Oque será? A Flor da Pele. Música Popular Brasileira.

Kelsen, H. (1974). A Teoria Pura do Direito. Coimbra: Armênio Amado.

Lacan, J. (1975). Clôture des Journées des Cartels. Lettres de f'École Freudienne, $\mathrm{n}^{0} 18$, Paris.

Lacan, J. (1995). A relação de objeto. Em O Seminário 4. Rio de Janeiro: Jorge Zahar.

Legendre, P. (1983). L'Empire de la Verité. Paris: Fayard.

Legendre. P. (1983). O Amor do Censor, Ensaio sobre a Ordem Dogmática. Rio de Janeiro: Forense / Uiversitária / Aoutra / Colégio Freudiano.
Silva, C. M. da. (1997). Defesa do Cidadão. Jornal O Clobo, página de Betch Cleinman, em 15/11.

Barros, F. O. de. (1997). Interdisciplinaridade, uma visita ao Tribunal de Família pelo Olhar da Psicanálise. Em Direito de Família Contemporâneo. Belo Horizonte: Del Rey.

Barros, F. O. de. (1996). "Cada cabeça, uma sentença" - O litígio Conjugal. Em Psiquê, n8, maio. Faculdades Integradas Newton Paiva.

Phillippi, J. N. (1994). Direito e Psicanálise - Um diálogo com o pensamento Pierre Legendre. Alter Ágora, 1, maio. Florianópolis.

Pommier, G. (1990). O desenlace de uma análise.

Rio de Janeiro: Jorge Zahar.

Pommier, C. (1992). A Neurose Infantil da Psicanálise.

Rio de Janeiro: Jorge Zahar.
Referências
bibliográficas 